UNIVERSITY of NORTH FLORIDA.

\section{Journal of Counseling Sexology \& Sexual Wellness: Research, Practice, and Education}

Volume 1 | Issue 1

Article 4

\title{
Counseling the Kink Community: What Clinicians Need to Know
}

Stephanie M. Yates

Northwestern University

Anita A. Neuer-Colburn

Northwestern University

Follow this and additional works at: https://digitalcommons.unf.edu/jcssw

Part of the Counseling Commons, and the Counseling Psychology Commons

\section{Recommended Citation \\ Yates, S. M., \& Neuer-Colburn, A. A. (2019). Counseling the Kink Community: What Clinicians Need to Know. Journal of Counseling Sexology \& Sexual Wellness: Research, Practice, and Education, 1 (1). https://doi.org/10.34296/01011007}

This Article is brought to you for free and open access by the Brooks College of Health at UNF Digital Commons. It has been accepted for inclusion in Journal of Counseling Sexology \& Sexual Wellness: Research, Practice, and Education by an authorized administrator of UNF Digital Commons. For more information, please contact Digital Projects.

() 2019 All Rights Reserved

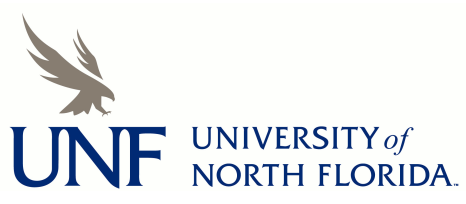




\title{
Counseling the Kink Community: What Clinicians Need to Know
}

\author{
Stephanie M. Yates \\ Northwestern University
}

\author{
Anita A. Neuer-Colburn \\ Northwestern University
}

\begin{abstract}
Recent media portrayals of Kink are prevalent, but not always culturally accurate and can perpetuate a stigma that impacts the therapeutic environment when working with Kink-oriented individuals. Misunderstanding the culture can increase prejudice, misdiagnosis, and maltreatment of Kink-oriented clients. The authors provide readers with an introductory primer on language used within the Kink culture, avoiding the pathology of cultural and personal preferences, and myths associated with Kink community practices. Implications for best practices are offered.
\end{abstract}

Keywords: kink, BDSM, cultural sensitivity

\section{Introduction}

In recent years, pop culture (music, films, and literature) exposure of alternative sexualities and lifestyles have increased, with particular attention being paid to the Kink community. Examples of this includes popular fiction novels such as "Fifty Shades of Grey" (James, 2011), films such as "The Secretary" (Fierberg, Hobby, \& Shainberg, 2002), and songs such as "S\&M" (Dean, Eriksen, Hermansen, \& Wihelm, 2010). Unfortunately, these portrayals are not always accurate and may contribute to increased negative stereotyping of a community still fighting for equal rights and protection. Kink is not a new concept and has been found in literature and artistic portrayals for centuries, dating as early as ancient texts to present day (Bolin \& Whelehan, 2015). However, increased social awareness has brought this community and their practices into the forefront of media attention.

Perpetuated stigma has led to obstacles for members of the Kink community to obtain rights and protection within the judicial system in regard to child custody, discrimination, prejudice, and mistreatment (Lin, 2016). The stigma also interferes with obtaining culturally sensitive and evidencebased practices in the therapeutic setting, despite recent significant changes to the Diagnostic Statistical Manual-5 in 2013 (American Psychiatric Association, 2013; Wright, 2006). Early versions of the manual classified individuals within the Kink community as "deviant" or labeled kink practitioners as having a paraphilic disorder, contributing to the stigmatization of this population by professionals (Bezreh, Weinberg, \& Edgar, 2012). It may be that a skewed or limited understanding of the population could be the cause.

While many professionals and experts have stated their definition of Kink, there is not currently an established and unanimously agreed upon definition for the kink community or its practices. The most recent definition of Kink in the Merriam-Webster Dictionary (2018) defines "Kink" as "unconventional sexual taste or behavior." Experts within the
Kink community such as Miller and Devon (1995) defined Kink as "sexual practices that go beyond what are considered conventional as a means of heightening the intimacy between sexual partners." Other experts such as Taormino (2012) have defined Kink as a "term that covers BDSM, sadomasochism, kinky sex, dominance and submission, role play, sex games, fantasy, fetish, and other erotic expressions." Popp and Kaldera (2014) define kink as "A general term for the practice of BDSM and/or a number of paraphilias, including but not limited to fetishistic cross-dressing, unusual sexual roleplaying, or sexual arousal from items other than a human body. However, most people who identify as 'kinksters' learned that term in the BDSM demographic and use it to describe those activities" (p. 6). Each of these definitions emphasizes the alternative sexuality of the lifestyle but does not do justice to the deeper contexts of the culture embedded in the community's values, customs, and social normative behaviors.

The alternative sexual practices of the Kink community can often overshadow the fact that the community has its own set of belief systems, values, social norms, practices, ceremonies, organizations, customs, and ways of understanding (Moore, Pincus, \& Rodemaker, 2018). The Kink community has artwork and emblems unique to these values as well as their own rituals and hierarchy (Jozifkova, 2013). Kink-

\begin{tabular}{|c|}
\hline Corresponding Author \\
\hline Stephanie Yates \\
Northwestern University \\
7011 Thomas Dr. \\
Loves Park, IL 61111 \\
E: psychd917@ gmail.com \\
P: (815)200-7640 \\
\hline
\end{tabular}


oriented individuals also have a unique set of terminology and language that they understand differently than individuals outside the community (Moore et al., 2018). To be effective helping professionals, counselors must understand that Kink is more than the sexual interactions prominently displayed and advertised by pop culture. Instead, Kink is actually a thriving culture based on acceptance, communication, trust, empowerment, and fulfillment.

Therefore, the purpose of this paper is to offer guidance and resources for clinicians working with individuals who identify as members of the Kink community. This resource will enable clinicians to reframe their understanding of Kink in order to treat individuals within this community based on cultural sensitivity and protect them from additional discrimination, prejudice, abuse, and residual effects of societal isolation. We will explore important subjects such as terms and language used within the Kink culture, avoiding the pathology of cultural and personal preferences, and myths associated with Kink community practices. Finally, we will offer best practices for clinicians providing services to members of the Kink community.

\section{Terms}

We define Kink as a culture or lifestyle outside of the social norm centered around consensual non-egalitarian relationship practices, concepts of monogamy, sexual interactions, sexual activities and/or fantasies as a means for heightened intimacy between partners. In contrast, groups and individuals who do not identify with BDSM as part of their identity are known as vanilla. This term will be used to define individuals who follow social norms in their relationship styles, sexual practices, and sexual activities. While it may seem there is a defined boundary, readers should keep in mind that the line between "Kink" and "vanilla" is arbitrary and spectral in that it depends on how an individual identifies (Taormino, 2012), much like the commonly known spectrum of sexuality. One can identify as "vanilla" while enjoying an occasional kink activity just as a heterosexual female may occasionally have intimate contact with other women but identify as "straight." Therefore, social norm in this context is to be understood as the nature of modern-day relationships in terms of non-stigmatized relationships and what is considered acceptable and/or appropriate behavior within dominant society. The term culture will also be understood as the belief systems and value orientations that influence customs, norms, practice, and social situations, including psychological processes and organizations (Sue \& Sue, 2016).

\section{BDSM}

Merriam-Webster Dictionary (2018) inaccurately defines BDSM as "sexual activity involving such practices as the use of physical restraints, the granting and relinquishing of control, and the infliction of pain." BDSM is actually, however, the overlapping acronym for bondage and discipline (BD the use of physical or psychological restraints), dominance and submission (DS or D/s - active participation in the consensual and negotiated exchange or handing over of power or authority to another), sadism and masochism or sadomasochism (SM or S\&M - engaging in activities that involve intense or strong sensation and/or stimuli) (Ambler et al., 2017; Jozifkova, 2013). Community members do not, however, necessarily take part in all of these components. Rather, members may participate or identify with any one or more of the components of BDSM at any given time (P. Miller \& Devon, 1995). Those within the Kink community tend to understand that BDSM is a large part of identifying as Kink for the majority of members, and so the terms Kink and BDSM can be interchangeable as well as exclusive terms in community terminology (Taormino, 2012; Sagarin, Cutler, Cutler, Lawler-Sagarin, \& Matuszewich, 2008). It is also commonplace for community members to have explicit and detailed discussion to ensure a safe and consensual relationship and/or interaction (Wiseman, 1996). Discussion is especially important since much of the practice of BDSM requires careful and cautious communication that includes what someone will or will not be interested or willing to participate in to identify hard limits (that which someone will absolutely not do) and soft limits (activities that are not preferred, but may be considered with the right partner(s) under the right circumstances; Klement, Sagarin, \& Lee, 2016; Wiseman, 1996).

BDSM relationships can be strictly negotiated and specified with a determined end date/time, or long term with an ongoing dynamic. No matter the temporary or permanent nature of the relationship itself, activities are still typically conducted in a safe, negotiated space over a specific period (Williams, Thomas, Porter, \& Christensen, 2014). Long, formal activity sessions where two or more people come together in a planned session to practice BDSM are known as scenes while the actual practice, use of tools, and use of skill related to BDSM activities conducted within the scene is known as play (Popp \& Kaldera, 2014; Wiseman, 1996). It is also very important to note that playing and "scenes" do not always include sexual contact or interaction. BDSM interactions can be physical, emotional, psychological, spiritual, or any combination of these (P. Miller \& Devon, 1995; Taormino, 2012; Wiseman, 1996).

Scenes and certain relationship styles often include an act that is termed a power exchange. Power exchange is the willful, consensual, and negotiated exchange of power or authority from one unit or person to the other(s) (Moore et al., 2018). The period following the scene or play time in which participants receive physical, emotional, and psychological care and debrief with their partner(s) is known as aftercare. This can manifest as cuddling and tenderness or as a water break with chocolate treats. No matter the manifestation, 
there is a detailed discussion of how the scene was or was not successful as well as the reactions each participant experienced (Sagarin et al., 2008). Aftercare is not seen by the Kink community as optional, but rather as a duty and a responsibility of the top toward the bottom. In fact, one study identified that the average scene lasts 55 minutes while the average aftercare lasts 19 minutes, which is roughly one third of the time spent in the actual activity (Ambler et al., 2017). This support can correspond to the ethical responsibility of a clinician to follow up and support a client following a particularly intense therapeutic session.

The roles, in their basic forms, typically involve that of a Dominant (Dom/Domme), Submissive (sub), Service Top (Top), Service Bottom (bottom), and Switch (Popp \& Kaldera, 2014; P. Miller \& Devon, 1995; Taormino, 2012). The Dom/me exerts control over a submissive and may direct him/her/hir to complete tasks, behave a certain way, obey certain commands, or submit to various kinds of SM. The sub voluntarily, with explicit consent, surrenders control to the Dom/me, complies with the dominants wishes, follows orders, and finds fulfillment in pleasing, serving, and caring for the dominant. The role of a Top takes on a similar role as a Dom/me but is limited to a time period expressly for the purpose of scene and/or play. Similarly, a bottom takes on the role of a sub for a limited and negotiated time period but sheds the role when the scene/play concludes. A switch is an individual who takes on any of the aforementioned roles but may prefer certain roles over others. It is important to note that there are multiple sub-categories and sub-cultures within BDSM roles, relationships, and practices, too many to identify in one article. As with any culture or form of identity, labels and titles can change based on perception and how an individual identifies that role.

\section{Pathologizing vs. Pathology}

In response to recent advocacy movements benefiting alternative sexualities, the American Psychiatric Association (APA; 2013) updated the latest version of the "Diagnostic and Statistical Manual of Mental Disorders" to reflect the difference between paraphilic disorders and the culture of Kink. Diagnoses such as Voyeuristic Disorder, Exhibitionistic Disorder, Fetishistic Disorder, Sexual Sadism Disorder and Sexual Masochism Disorder were changed such that they must include criteria such as presence of distress exemplified by anxiety, guilt, shame, and obsessions surrounding the symptoms/behaviors that interfere with important areas of functioning in order to be diagnosable. Sexual Sadism Disorder, Voyeuristic Disorder, and Exhibitionistic Disorder also require the criterion of being enacted against another individual without their consent. Without the presence of these criteria, the APA (2013) states that individuals can be termed as having a "relatable sexual interest" but not as having a disorder (p. 685-686).
The practices of Kink community members hinge on one central construct: consent (Wiseman, 1996). Kink-oriented individuals adhere to strict values and belief systems to protect the community and its members. These cornerstones include radical honesty, candid communication, expressed consent, safety practices, trust, and full knowledge and disclosure of risk (Moore et al., 2018; Pitagora, 2013; Taormino, 2012; Tripodi, 2017; Wiseman, 1996). The Kink community adopted their own set of principles that represent the core values, which include consent, negotiation, safety and risk reduction, communication, and aftercare (Taormino, 2012). A common phrase to encompass these values within the Kink community is the motto of "Safe, Sane, and Consensual" (Williams et al., 2014). Of these values, the one of highest importance is that of consent (Jozifkova, 2013; Tripodi, 2017; Williams et al., 2014).

Consent is the hub of the belief system observed by Kinkoriented individuals. When in social situations, all interactions are candidly and carefully negotiated and not enacted until enthusiastic consent, defined as "an active collaboration for the benefit, well-being, and pleasure of all persons concerned" (Wiseman, 1996, p. 8) is received (Taormino, 2012; Tripodi, 2017; Wiseman, 1996). Consent starts in prenegotiation when participants identify what activities they are willing to do, for how long, with whom, and in what way (Klement et al., 2016). If an activity or interest is not discussed and happily agreed upon, it is not an option for that period of time and interest should be brought up as an option for future scenes during aftercare. Consent is also not assumed throughout the negotiated interactions and steps are taken to assure that an individual or group of individuals are always able to halt or pause interactions through the use of safe words and/or safe gestures (Ambler et al., 2017; Jozifkova, 2013; Klement et al., 2016; Wiseman, 1996). The use of a safe word or safe gesture automatically removes consent and commands a halt to activities (Pitagora, 2013). Responsible practitioners will also consistently check in to garner further consent and reactions throughout all interactions (P. Miller \& Devon, 1995; Taormino, 2012; Tripodi, 2017; Wiseman, 1996).

Another key difference between paraphilic pathology and Kink culture is in the motivation. Kink-oriented individuals will likely report that their motivation is not only to serve their sexual and relationship needs, but to fulfill their need for intimacy and closeness while meeting the same needs for their partner (Sagarin et al., 2008). Relationships within the Kink culture are heavily reliant on vulnerability and open, honest, communication. Kink practitioners are encouraged, and at times required, to discuss the depth of their feelings, fantasies, fetishes, desires, and longings (Klement et al., 2016). Those who participate in dominant and submissive play particularly engage in activities that build intense feelings of trust and accountability (Tripodi, 2017). Such 
motivations and communication lead to strong feelings of intimacy and bonding (Sagarin et al., 2008). Therefore, if a client were to express sexual excitement over physically hurting or humiliating a nonconsenting person, psychopathology and abuse is likely present (Dunkley \& Brotto, 2018).

\section{Debunking the Myths of Kink}

As with most cultures, one key to combating bias and prejudice is to understand and debunk the myths and stereotypes that surround Kink culture. The myths and stereotypes surrounding the culture and subcultures of the Kink community have greatly impacted its members (Wright, 2008b). Among these myths are common beliefs that Kink-oriented individuals are deviant or mentally ill, tend to be violent or emotionally unstable, perpetuate the subjugation of women, are unable to have stable and healthy relationships, and tend to be uneducated (Bezreh et al., 2012; Connolly, 2006; Cross \& Matheson, 2006; Gemberling, Cramer, Wright, \& Nobels, 2015; Klement et al., 2016; Lin, 2016; Wright, 2006). These myths have been perpetuated beyond social stigma into misguided practice by helping professionals (Bezreh et al., 2012; Connolly, 2006; Gemberling et al., 2015; Sandnabba, Santtila, Alison, \& Nordling, 2002; Sprott, Randall, Davison, Cannon, \& Witherspoon, 2017; Richters, Visser, Rissel, Grulich, \& Smith, 2008; Waldura, Arora, Randall, Farala, \& Sprott, 2016; Wismeijer \& van Assen, 2013; Wright, 2006).

A study conducted by the National Coalition for Sexual Freedom (2008) outlined the prevalence of discrimination and stigma against members of the Kink culture showing that approximately $49 \%$ of the 3,058 respondents reported discrimination by a medical professional, 39\% reported discrimination by a mental health professional, and $25 \%$ by a police or government officer. The respondents also reported instances of loss of jobs and/or contracts (20\%), refusal of service (19\%), divorce or separation (13\%), loss of promotion and/or demoted (12\%), and loss of child custody (6\%). In addition, findings revealed that $35 \%$ of respondents reported loss of friends, alienation, refusal of entertainment and celebration venue rental, refusal of use of public spaces, and denial of permits for peaceful protest or picketing for erroneous reasons. Most kink-oriented individuals hide their affiliation/preferences for the Kink culture, with only a little over one third of the population reporting being "out" in some way (Sprott et al., 2017). To change these numbers and instances of discrimination counselors must become educated and culturally aware of the Kink community. This can be done through the correction of perpetuated myths surrounding the Kink culture.

\section{Mental Illness}

One such myth of kink is the belief that Kink-oriented individuals tend to be mentally ill or sexually deviant. According to recent studies, the Kink population samples seem to exhibit equivalent or healthier levels of depression, selfesteem, sexual difficulties, obsession-compulsion, attachment styles, posttraumatic stress, family background, personality disorders, anxiety, and overall risk for mental instability (Connolly, 2006; Cross \& Matheson, 2006; Gemberling et al., 2015; Sandnabba et al., 2002; Richters et al., 2008; Wismeijer \& van Assen, 2013). The prevalence of common mental disorders such as mood and stress disorders shows little to no difference across populations with slight exceptions for members of the LGBTQ community, as also seen in the general population (Wismeijer \& van Assen, 2013). One current hypothesis for the slight exception in the LGBTQ community is that these individuals are battling compounded prejudice and discrimination for their sexual orientation as well as for their identification with the kink culture, which may be adversely affecting mental health. General results in recent studies, however, state that Kink-oriented individuals do not seem to be experiencing serious mental health problems that are significantly different from the general population which includes the LGBTQ community (Gemberling et al., 2015). These studies indicate that Kink practitioners in comparison to the general population tend to have the same rates of mental illness and psychological distress (Connolly, 2006; Cross \& Matheson, 2006; Richters et al., 2008). Kink practitioners also tend to be more open to new experiences, less neurotic, and more conscientious in comparison to the general population (Wismeijer \& van Assen, 2013).

Another study indicated that Kink-oriented desires and fantasies seem to arise during the normal period of sexual development (Bezreh et al., 2012). The majority of individuals experience the emergence of Kink directed desires between childhood and into their twenties. Kink-oriented individuals do not seem to report any significant distress in their sexual interests and desires (Waldura et al., 2016); rather, they report distress regarding mistreatment and discrimination by individuals who do not understand or participate in the Kink lifestyle (Wright, 2006).

\section{Violence}

Another myth suggests that Kink-oriented individuals tend to be violent and emotionally unstable. In reality, the culture of Kink is so centered around consent that most respondents from a 2008 study share instances of violence and assault from individuals outside of the Kink community rather than from those within the community (Wright, 2008). Instances of abuse within the community typically occur when an individual purposely disregards a safe word or dishonors a hard limit; this is typically a direct result of ignorance, lack of skill/training in the community, or erroneous stigmas regarding the population (Jozifkova, 2013). Wright (2006) backs this finding up with a national survey indicating that violence, abuse, and harassment are typically perpetrated by those outside of the community, or strangers preying on 
members of the community via community resources such as Kink-specialized websites. There is a concern that the need for secrecy to protect community members from mistreatment and discrimination has brought about a rise in anonymous interactions via web, putting kink-oriented individuals at risk. This is evidenced by reports within the survey of $22 \%$ of 680 respondents being victims of violence and/or harassment and yet a concerning $96 \%$ of those victimized reported not filing or pressing charges due to fear of discrimination (Wright, 2008).

The most recent study of the Kink population indicated that less than $3 \%$ of the 816 respondents reported having been the perpetrator of some form of physical assault (Gemberling et al., 2015). This and other studies have indicated consistent results that Kink-oriented individuals score equivalently or lower in areas of hostility, authoritarianism, psychopathological sadism and masochism, and psychopathy (Wismeijer \& van Assen, 2013; Wright, 2008). The research suggests that Kink-oriented individuals are not a significant risk in terms of dysfunctions and violence perpetration (Connolly, 2006; Cross \& Matheson, 2006; Gemberling et al., 2015).

The cycle of BDSM interaction follows a separate path than that of abuse and portrays significant differences (Jozifkova, 2013). BDSM practices are purely voluntary with extensive negotiation regarding the activities that are later enacted (Klement et al., 2016; Pitagora, 2013; Taormino, 2012; Tripodi, 2017). BDSM also includes the ability to communicate likes, dislikes, changes, and a safe word to stop all activities. There is also the presence of safe sex practices and the ability to limit risks to health and safety. Participants are able and encouraged to access information and resources for learning and training in specific techniques and activities (Klement et al., 2016; Popp \& Kaldera, 2014; Taormino, 2012). Added to these differences is the psychological effect of the interactions that result in satisfaction, stress relief, and intimacy (Jozifkova, 2013). A primary goal of Kink-oriented individuals is to seek empowerment and self-actualization not only for themselves but for their partners as well (Sagarin et al., 2008; Tripodi, 2017; Wiseman, 1996).

In contrast, victims of violence and abuse typically portray psychological changes including lower self-esteem, helplessness, fear, and internalizing blame (R. Miller, 2011). Abuse also tends to follow a cycle in which there is a period of tension followed by the explosion during which the abuse takes place, followed by guilt and/or rationalization where the perpetrator typically blames the victim. Finally, there is a period of calm or a "honeymoon" stage during which the perpetrator acts with kindness and affection while the victim is lulled into a false sense of security (Jozifkova, 2013).

The BDSM cycle is different in that it starts with honest communication and negotiation where activities are dis- cussed and agreed upon by both parties (Tripodi, 2017; Williams et al., 2014). The next stage is the scene or play activity which can be stopped at any time by either participant using a previously agreed upon code word or gesture (Taormino, 2012). The focus of the scene or play is for each participant to provide for the need and pleasure of the other(s) involved in a symbiotic fashion (Wiseman, 1996). No matter the length or success of the scene or play, aftercare follows to provide comfort and care, an opportunity to debrief what was good, bad, or neutral about the experience, and to check on the emotional and mental reactions (Jozifkova, 2013). Aftercare is personalized for those involved and can involve platonic discussion, a drink of water, intimate intercourse, or cuddling (Klement et al., 2016; Wiseman, 1996).

\section{Female Subjugation in BDSM}

Another popular myth surrounding Kink culture is that it subjugates women and promotes male chauvinistic behavior. The most recent national survey of Kink-identifying individuals indicated that $51 \%$ of respondents identified as primarily female (Gemberling et al., 2015). Of the total respondents, only about $38 \%$ of the sample reported a primarily submissive identity. It is important to note, however, that the term 'submissive' can be misleading in that it is actually the submissive who holds the majority of control over the negotiated interactions no matter their gender (Tripodi, 2017). The sub can request to be released from a dynamic or state their safe word at any time to interrupt, discuss, or discontinue any distressing practices.

The Kink community is open and accepting of all identities regardless of individual gender, gender identity, sexual orientation, or preference (Taormino, 2012). Women are encouraged to pursue their desires and become empowered in their sexuality (Tripodi, 2017). A recent study interviewed pro-dommes, women who act professionally in a dominant role, and indicated that the women felt fulfilled, accepted, and satisfied in their roles (Lindemann, 2011). Tripodi (2017) also found that bottoms and submissives feel that the act of submission actually increases sexual agency and empowerment through intimacy. This is something often achieved through power exchange when one or more individual relinquishes power to the leader and receives a sense of power in return since the follower(s) can take back their authority at any time with a word or gesture. This act of giving and receiving of levels of empowering intimacy is done through careful negotiation and communication (Moore et al., 2018).

\section{Lack of Healthy and Committed Relationships}

Kink culture places a great deal of emphasis on intimacy (Taormino, 2012). The culture, however, is misunderstood to be of a promiscuous and commitment avoiding nature. 
Empirical evidence proves the opposite to be true. Demographics gathered in a recent survey of the Kink community revealed that $30 \%$ of respondents reported being married and/or in a lifelong commitment. About $28 \%$ of respondents reported being in a serious relationship while roughly $28 \%$ of respondents reported being either single or casually dating. The remaining $14 \%$ of respondents reported being in 'other' forms of relationships which include polyamorous and open relationships (Gemberling et al., 2015).

Healthy, functional, and long-lasting relationships are not rare, even in 24/7 intensive dominance and submission relationships (Dancer, Kleinplatz, \& Moser, 2006). Couples report increased feelings of contentment, closeness, and trust following consensual interactions (Sagarin et al., 2008). Participants also exhibited reduction in physiological stress following a successful scene or play session. Healthy relationships outside of scenes and play are evident in individual characteristics such as absence of fear and/or recoil, lack of feelings surrounding guilt and worthlessness, evidence of respect for partner(s), ability to distinguish and separate scene and play activities from real life actions, absence of failure and compensation cycle, evidence of stable behavior, lack of isolating behaviors, lack of aggression toward partner(s), and only a mild hierarchy disparity between partners (Jozifkova, 2013).

\section{Lack of Education}

Demographic studies not only indicate stability in relationships, but in socioeconomic domains. A study conducted with the support of the National Coalition for Sexual Freedom (Gemberling et al., 2015) revealed that roughly $60 \%$ of Kink culture respondents reported having a bachelor's degree or higher. Roughly $18 \%$ of respondents reported having an Associate's or Vocational degree. In the same study, $59 \%$ of the respondents reported individual annual income over $30 \mathrm{~K}$. These numbers seem to corroborate similar demographic studies (Waldura et al., 2016; Wright, 2008). Tripodi (2017) hypothesized that, due to the high cost related to Kink activities and tools, active participation in the lifestyle requires a certain socioeconomic status.

\section{Discussion}

Recently, conversion therapy has been discredited and is in the process of being banned through legislature in specific states within the United States (Frankel, 2017). Though the premise of conversion therapy is historically understood as relating to the LGBTQ community, the action of treating Kink as pathological can have similar negative effects (Wright, 2008). Professionals are becoming aware of the harmful effects that conversion therapy and attempting to change an individual's sexuality can have on clients (Sue \& Sue, 2016). Often, treatment of Kink-oriented individuals results in the erroneous diagnosis of a paraphilic or other disorder (Lin, 2016). The stigma and non-inclusion of Kink in sessions can also be correlated to poorer treatment outcomes and poorer client retention (Sprott et al., 2017; Wright, 2006). As a result, there has been great movement toward changing the stigma of Kink culture as a disorder.

What the stigma and stereotypes of this group fail to address is the impact the mistreatment of this culture holds for community members beyond their sexual practices. Waldura and colleagues (2016) discovered that 78\% of Kinkoriented respondents reported the lifestyle as having affected their mental health, indicating that their mental health is intrinsically tied to many Kink-oriented individuals' subjective well-being. Of these respondents, $85 \%$ reported a positive impact, $13 \%$ reported both positive and negative impacts, and only $1 \%$ reported a negative impact. Another study indicated that Kink-oriented individuals tend to seek helping professionals based on referrals within the community due to fear of stigma and mistreatment (Lin, 2016). Some literature also suggests that individuals will avoid seeking treatment at all from medical and mental health professionals for the same reason (Waldura et al., 2016).

The American Counseling Association's Code of Ethics (2014) in section E.5.b compels counselors to use cultural sensitivity when considering or diagnosing a mental disorder. Section E.5.c. of the Code of Ethics further implores counselors to recognize historical and social prejudices that lead to the misdiagnosis or pathologizing of certain groups and individuals. Counselors are to strive for awareness of any bias and/or prejudice within themselves or others in order to provide quality care (American Counseling Association, 2014). A misdiagnosis can cause irreparable harm to the client by impeding and infringing on their agency, autonomy, and individual identity. When treating a client is not possible, it is the professional's responsibility to refer the client to a professional who can provide quality care (American Counseling Association, 2014; Sue \& Sue, 2016). Clinicians should then pursue training and cultural competency seminars to ensure clinicians can work through bias/prejudice to be better prepared for future clients.

Further harm can be done if helping professionals are unaware of the differences between cultural context and constructs such as pathology, abuse, stigma, and dysfunction. Kink-oriented individuals report losing child custody battles, jobs, livelihoods, promotions, and educational opportunities as a result of disclosing their Kink orientation (Bezreh et al., 2012; Wright, 2006). Since helping professionals are also mandated reporters, knowledge of the cultural context for Kink-oriented individuals is necessary prior to concluding abuse is occurring (Jozifkova, 2013). Operating without awareness and sensitivity in regard to this culture resulting in the harmful labels as well as the suppression and oppression of a client's self-actualization, self-acceptance and identity, quality of life, basic rights, health, and happiness is hardly 
doing good.

\section{Implications}

Current research of Kink-oriented clients and their experiences in counseling is limited at this time. Among the most recent surveys covering this concern was a study that was completed in 2008. The Second National Survey of Violence and Discrimination Against Sexual Minorities identifies reports of clients being refused service until the client acknowledged and became willing to work on the abuse the professional felt was occurring (Wright, 2006). Many reported being diagnosed with a paraphilic disorder and told that they would need treatment to lead a productive life. Other Kink community members are reporting instances of managing negative and insensitive comments, battling misconceptions about Kink, and struggling against stigmas of violence and abuse in therapeutic environments (Dunkley \& Brotto, 2018).

Situations such as these show the importance and need for further research and education among helping professionals. Due to the impact this culture has on a client's well-being in all domains, counselors should be required to learn about, and become comfortable with, treating individuals who identify as having alternative lifestyles and sexualities. Additionally, since sexuality plays such a large role in the human condition, all programs would do well to require Human Sexuality courses with specific curriculum for competency with treating clients who identify with alternative lifestyles and sexualities (Dunkley \& Brotto, 2018). Rodemaker (2014) calls for this when challenging organizations to offer more training for graduate students, specialized continuing education, and cultural sensitivity courses due to the lack of basic skills and comfort level required to treat this population.

Counselors should approach their work with Kinkoriented clients through a cultural lens, considering the impacts of specific culture on habits, interactions, expressions, and language. Educators and supervisors should encourage counselors to approach their sessions with curiosity and openness rather than being pathology minded. Tarshis (2014) challenges counselors to be self-aware because "when we are distracted (or uncomfortable, or appalled) we can miss the bigger picture and fail to serve a person who we are, in fact, entirely capable of serving" (p. 16). The simple solution according to Tarshis (2014) is to remember that each kinkoriented individual has issues similar to anyone else's and to not get "hung up" on the kinky sex. In short, counselors are called to focus on the client's perception of normal rather than the counselor's perception of normal. A simple way to achieve this is to adopt the philosophy when in Rome (or Kink) talk as the Kinksters do. Clinicians should be comfortable with explicit, candid conversations about how the client identifies with kink as a term, preference, or lifestyle, and be open to myriad definitions.
To do this, counselors must view client concerns from an objective, client-focused angle. Since safety is a large consideration, counselors should be comfortable with determining how consensual interactions are and know enough to be able to tell the difference between abuse and consensual practice. Rodemaker (2014) called counselors to refrain from viewing clients with assumptions of what should or should not be considered a healthy relationship based on counselor preferences and instead focus on empirically based facts that determine what constitutes potential or evidence of an abusive relationship. Such factors include tendency toward high conflict, poor impulse control, feelings of worthlessness, entrapment, lack of consent, and distress (R. Miller, 2011; Rodemaker, 2014).

Finally, competency with the Kink-oriented population requires specific training. Counselors can and should identify resources to aid their understanding of the culture and practices of this unique population. Counselor educators, supervisors, and practicing counselors should be aware of resources such as books, articles, trainings, and kink friendly professionals with whom to consult. More trainings regarding kink culture are also being offered at conferences and in seminars with the prevalence of media attention. Counselors can find as well that Kink aware and Kink friendly resources are made available at the website for the National Coalition for Sexual Freedom (2019). These resources are available for counseling professionals as well as kink-identifying individuals.

\section{References}

Ambler, J. K., Lee, E. M., Klement, K. R., Loewald, T., Comber, E. M., Hanson, S. A., ... Sagarin, B. J. (2017). Consensual BDSM facilitates role-specific altered states of consciousness: A preliminary study. Psychology of Consciousness: Theory, Research, and Practice, 4(1), 75-91. doi:10.1037/cns0000097

American Counseling Association. (2014). Code of ethics. Author.

American Psychiatric Association. (2013). Diagnostic and statistical manual of mental disorders, 5th edition: Dsm-5. American Psychiatric Publishing.

Bezreh, T., Weinberg, T. S., \& Edgar, T. (2012). BDSM disclosure and stigma management: Identifying opportunities for sex education. American Journal of Sexuality Education, 7(1), 37-61. doi:10.1080/15546128.2012.650984

Bolin, A., \& Whelehan, P. (Eds.). (2015). The international encyclopedia of human sexuality. John Wiley \& Sons, Ltd. doi:https://doi.org/10.1002/9781118896877.wbiehs043

Connolly, P. H. (2006). Psychological functioning of bondage/domination/sado-masochism (BDSM) practi- 
tioners. Journal of Psychology \& Human Sexuality, 18(1), 79-120. doi:10.1300/j056v18n01_05

Cross, P., \& Matheson, K. (2006). Understanding sadomasochism: An empirical examination of four perspectives. Journal of Homosexuality, 50, 133-166.

Dancer, P. L., Kleinplatz, P. J., \& Moser, C. (2006). 24/7 SM slavery. Journal of Homosexuality, 50(2-3), 81101. doi:10.1300/j082v50n02_05

Dean, E., Eriksen, M. S., Hermansen, T. E., \& Wihelm, S. (2010). SEFm. Recorded by Rihanna.

Dunkley, C. R., \& Brotto, L. A. (2018, March). Clinical considerations in treating BDSM practitioners: A review. Journal of Sex $\mathcal{E}$ Marital Therapy, 1-12. doi:10.1080/0092623x.2018.1451792

Fierberg, A., Hobby, A., \& Shainberg, S. (2002). The secretary. Lions Gate Films.

Frankel, J. (2017, 7). More and more states are outlawing gay-conversion therapy. The Atlantic. Retrieved from https://www. theatlantic.com/ health/archive/2017/07/states-outlawing -conversion-therapy/533121/

Gemberling, T. M., Cramer, R. J., Wright, S., \& Nobels, M. R. (2015). Psychological functioning and violence victimization and perpetration in bdsm practitioners fromthe national coalition for sexual freedom (Tech. Rep.). National Coalition for Sexual Freedom. Retrieved from https://pdfs. semanticscholar.org/0cd8/ abb591fda8685091c1f208bc757d616f0903.pdf

James, E. (2011). Fifty shades trilogy bundle. Vintage.

Jozifkova, E. (2013, August). Consensual sadomasochistic sex (BDSM): The roots, the risks, and the distinctions between BDSM and violence. Current Psychiatry Reports, 15(9). doi:10.1007/s11920-013-0392-1

Kink. (2018). Merriam-Webster Online Dictionary. Merriam-Webster.

Klement, K. R., Sagarin, B. J., \& Lee, E. M. (2016, April). Participating in a culture of consent may be associated with lower rape-supportive beliefs. The Journal of Sex Research, 54(1), 130-134. doi:10.1080/00224499.2016.1168353

Lin, K. (2016, September). The medicalization and demedicalization of kink: Shifting contexts of sexual politics. Sexualities, 20(3), 302-323. doi: $10.1177 / 1363460716651420$

Lindemann, D. (2011, April). BDSM as therapy? $\quad$ Sexualities, 14(2), 151-172. doi: $10.1177 / 1363460711399038$

Miller, P., \& Devon, M. (1995). Screw the roses, send me the thorns: The romance and sexual sorcery of sadomasochism. Mystic Rose Books.

Miller, R. (2011). Intimate relationships. McGraw-Hill Education.
Moore, L., Pincus, T., \& Rodemaker, D. (2018). What professionalsneed to know about bdsm. National Coalition for Sexual Freedom. Retrieved from https://www.ncsfreedom.org/images/ stories/pdfs/Activist/What_Professionals _Need_to_Know_About_BDSM_1.pdf

National Coalition for Sexual Freedom. (2019). Resources. Retrieved from https: //www.ncsfreedom - org/resources

Pitagora, D. (2013). Consent vs. coercion: Bdsm interactions highlight a fine but immutable line. The New School Psychology Bulletin, 10(1).

Popp, S., \& Kaldera, R. (2014). Unequal by design: Counseling power dynamic relationships. Asphodel Press.

Richters, J., Visser, R. O. D., Rissel, C. E., Grulich, A. E., \& Smith, A. M. (2008, July). Demographic and psychosocial features of participants in bondage and discipline, "sadomasochism" or dominance and submission (BDSM): Data from a national survey. The Journal of Sexual Medicine, 5(7), 1660-1668. doi:10.1111/j.1743-6109.2008.00795.x

Rodemaker, D. (2014). Understanding therapy issues outside egalitarian relationships. In S. Popp \& R. Kaldera (Eds.), Unequal by design: Counseling power $d y$ namic relationships (p. 24-37). Asphodel Press.

Sagarin, B. J., Cutler, B., Cutler, N., Lawler-Sagarin, K. A., \& Matuszewich, L. (2008, June). Hormonal changes and couple bonding in consensual sadomasochistic activity. Archives of Sexual Behavior, 38(2), 186-200. doi:10.1007/s10508-008-9374-5

Sandnabba, N. K., Santtila, P., Alison, L., \& Nordling, N. (2002, February). Demographics, sexual behaviour, family background and abuse experiences of practitioners of sadomasochistic sex: A review of recent research. Sexual and Relationship Therapy, 17(1), 3955. doi:10.1080/14681990220108018

Sprott, R. A., Randall, A., Davison, K., Cannon, N., \& Witherspoon, R. G. (2017, July). Alternative or nontraditional sexualities and therapy: A case report. Journal of Clinical Psychology, 73(8), 929-937. doi: $10.1002 / j c l p .22511$

Sue, D. W., \& Sue, D. (2016). Counseling the culturally diverse: Theory and practice. Wiley.

Taormino, T. (2012). The ultimate guide to kink: Bdsm, role play and the erotic edge. Cleis Press.

Tarshis, S. (2014). Counseling the power exchange couple: It's not as complicated as you think. In S. Popp \& R. Kaldera (Eds.), Unequal by design: Counseling power dynamic relationships (p. 16-23). Asphodel Press.

Tripodi, F. (2017, January). Fifty shades of consent? Feminist Media Studies, 17(1), 93-107. doi:10.1080/14680777.2017.1261846 
Waldura, J. F., Arora, I., Randall, A. M., Farala, J. P., \& Sprott, R. A. (2016, December). Fifty shades of stigma: Exploring the health care experiences of kinkoriented patients. The Journal of Sexual Medicine, 13(12), 1918-1929. doi:10.1016/j.jsxm.2016.09.019

Williams, D., Thomas, J. N., Porter, E. E., \& Christensen, M. C. (2014). From "ssc" and "rack" to the "4cs": Introducing a new framework for negotiating bdsm participation. Electronic Journal of Human Sexuality, 17, 1-10.

Wiseman, J. (1996). Sm 101: A realistic introduction. Greenery Press.

Wismeijer, A. A., \& van Assen, M. A. (2013, August). Psychological characteristics of BDSM practitioners. The Journal of Sexual Medicine, 10(8), 1943-1952. doi:10.1111/jsm.12192

Wright, S. (2006). Discrimination of sm-identifying individuals. Journal of Homosexuality, 50, 217-231.

Wright, S. (2008). Second national survey of violence \& discrimination against sexual minorities. National Coalition for Sexual Freedom. Retrieved from https://WWW.ncsfreedom.org/ images/stories/pdfs/BDSM_Survey/ 2008_bdsm_survey_analysis_final.pdf 